\title{
Infectivity of two nematode parasites, Camallanus lacustris and Anguillicola crassus, in a paratenic host, the three-spined stickleback Gasterosteus aculeatus
}

\author{
C. K. Krobbach' ${ }^{1}$ M. Kalbe ${ }^{1}$, J. Kurtz ${ }^{2}$, J. P. Scharsack ${ }^{1, *}$ \\ ${ }^{1}$ Department of Evolutionary Ecology, Max Planck Institute for Limnology, August-Thienemann-Straße 2, \\ 24306 Plön, Germany \\ ${ }^{2}$ University of Münster, Institute for Evolution and Biodiversity, Animal Evolutionary Ecology Group, Hüfferstr. 1, \\ 48149 Münster, Germany
}

\begin{abstract}
Three-spined sticklebacks Gasterosteus aculeatus are frequent paratenic hosts of the nematode parasites Anguillicola crassus and Camallanus lacustris. As paratenic hosts, sticklebacks could spread infection by carrying high numbers of infective stages. In contrast, low infective ability of either parasite for the paratenic host could hinder the spread of infection. In the present study, $G$. aculeatus was, for the first time, infected under controlled laboratory conditions with defined doses of the parasites. Sticklebacks were exposed to 6,12,18 and 24 parasite larvae to determine the infective ability of the 2 nematode species. There were significantly higher infection rates for $C$. lacustris (18 to $49 \%$ ) than for A. crassus (4 to $14 \%$ ) at each exposure dose. In C. lacustris-infected sticklebacks, infection rates tended to be highest after exposure to 12 C. lacustris larvae and lowest after exposure to 24 parasites. In A. crassus-infected sticklebacks, no effect of parasite exposure dose on infection rates was observed. Immunity parameters such as respiratory burst activity and lymphocyte proliferation of head kidney leukocytes recorded $18 \mathrm{wk}$ post exposure were not significantly affected by either parasite or exposure dose. Granulocyte:lymphocyte ratios were elevated only within the stickleback group showing the highest infection intensity of C. lacustris, i.e. to those exposed 18 parasites.
\end{abstract}

KEY WORDS: Anguillicola crassus · Camallanus lacustris · Gasterosteus aculeatus · Infective dose · Neozoic parasite $\cdot$ Immune response $\cdot$ Granulocyte:lymphocyte ratio $\cdot$ Respiratory burst

\section{INTRODUCTION}

The three-spined stickleback Gasterosteus aculeatus is the intermediate, paratenic or final host for several parasite species. Two of the most abundant parasites in sticklebacks in northern Germany are the nematodes Camallanus lacustris and Anguillicola crassus (Kalbe et al. 2002). Both parasites are transmitted by various copepod species as first intermediate hosts (Moravec 1994). For C. lacustris the final hosts are predatory fish such as pike Esox lucius or perch Perca fluviatilis (Moravec 1969a). In final as well as in paratenic hosts,
C. lacustris stays in the anterior part of the intestine, where it anchors in the mucosa causing inflammatory reactions (Moravec 1969b, Stumpp 1975, Lodes \& Yoshino 1985, Meguid \& Eure 1996).

Anguillicola crassus was endemic to East Asia, but has transferred from its original final host the Japanese eel Anguilla japonica to the European eel A. anguilla and the American eel A. rostrata (Kirk 2003). Anguillicola crassus penetrates the intestine of its paratenic and final hosts and migrates into the swim bladder. In its final eel host, A. crassus causes serious damage to the swim bladder tissue (Taraschewski et al. 1988, 
Molnar et al. 1995, Würtz \& Taraschewski 2000) and elicits cellular and humoral immune responses (Haenen \& van Banning 1990, Knopf et al. 2000, Mulcahy et al. 2005). In European eels, A. crassus can severely impair swim bladder function and, in the presence of other stressors, has caused mortalities in both farmed and wild populations (Kirk 2003).

Direct transmission to final hosts is possible for Camallanus lacustris and Anguillicola crassus, but frequently small planctivorous fishes (e.g. sticklebacks) are paratenic hosts in which both parasites persist without reproduction (Moravec 1994). The capability of paratenic hosts to control their parasite load can thus significantly influence the infection pressure of parasites on their final host (Rolbiecki 2004). To the best of our knowledge, parasite infections of paratenic fish hosts have not yet been investigated under controlled laboratory conditions in a dose-dependent manner. In the wild, abundance of Anguillicola crassus larvae varies among paratenic host fish species, but Thomas \& Ollevier (1992) observed higher prevalence in physoclist fishes (e.g. river goby, common perch), while physostome fishes (e.g. cyprinids) were less susceptible. The latter exhibit an effective immune response against $A$. crassus, resulting in encapsulation of invading larvae and formation of granulomas in which the parasites are killed (Szekely 1996). Although the three-spined stickleback is a frequent paratenic host of $A$. crassus (Haenen \& van Banning 1990, Thomas \& Ollevier 1992), little is known about its infective ability and dynamics.

Anguillicola crassus was introduced to Germany in 1982 (Neumann 1985), whereas Camallanus lacustris has long been established in lakes in northern Germany, probably since the last glacial period. This difference in the period of host-parasite co-evolution between the 2 parasites may be reflected in their ability to infect three-spined sticklebacks as paratenic hosts. In wild-caught sticklebacks, Kalbe et al. (2002) found a lower abundance (mean number of parasites per sampled fish) of A. crassus (0.645) than of C. lacustris $(0.748)$. It is not clear if this is due to differences in the infection pressure in wild populations, to differential immune responses of the stickleback or to differences in the infective ability of the 2 parasites.

Variations in the immune defense of hosts may depend on infection route, target organ and pathogenicity of the invading parasite (Buchmann et al. 2001, Tully \& Nolan 2002, Hoole et al. 2003, Roberts et al. 2005, Wiegertjes et al. 2005, Reite \& Evensen 2006). A major part of the innate immune defense of fish hosts against helminth parasites is the activation of granulocytes (Whyte et al. 1989, Nie \& Hoole 2000, Kurtz 2004, Scharsack et al. 2004). In addition to such innate defenses (Jones 2001), fish hosts possess adap- tive immunity that produces specific antibodies against parasite antigens (Roberts et al. 2005, Wiegertjes et al. 2005). Clonal expansion of lymphocytes is a fundamental part of the specific immune responses of fishes (Rijkers et al. 1980). Lymphocyte proliferation is used as a measure of the activation of the specific immune system against helminth and protozoan parasites (Hamers \& Goerlich 1996, Nie et al. 1996, Scharsack et al. 2000). The ratio of granulocytes to lymphocytes (G:L ratio) is used to determine the relative activity of innate versus adaptive immunity (Birkhead 1998, Kurtz 2004).

In the present study, we exposed sticklebacks to infective stages of Anguillicola crassus and Camallanus lacustris under laboratory conditions in order to determine differences in infective ability between the 2 parasite species. Infection was allowed to persist for $18 \mathrm{wk}$ to achieve a strong discriminatory power on parasite survival. Exposure to various infection doses revealed the parasite number that achieved optimal infection success. The condition of infected fish was recorded using the hepatosomatic index, and activation of their cellular immune system was measured as respiratory burst activity, proliferation of lymphocytes and the G:L ratio of the head kidney leukocytes.

\section{MATERIALS AND METHODS}

Parasites. Anguillicola crassus and Camallanus lacustris used in the infection experiments originated from host fish caught in the Grosse Plöner See (Germany) in autumn 2003 and spring 2004. Second stage larvae of $A$. crassus (L2) were washed out of freshly isolated swim bladders of eels Anguilla anguilla with phosphate bufffered saline (PBS). C. lacustris larvae were dissected from gravid female parasites collected from the intestinal blind sacks of perch Perca fluviatilis. Infective stages were stored overnight in glass petri dishes with $0.64 \% \mathrm{NaCl}$ at $6^{\circ} \mathrm{C}$.

Infection of copepods. As intermediate hosts, copepods Macrocyclops albidus from a parasite-free laboratory culture were prepared for infection as described by Hammerschmidt \& Kurtz (2005a). Each copepod assigned to a Camallanus lacustris or Anguillicola crassus treatment was offered 6 actively moving larvae of the relevant parasite. Infected copepods were kept singly in 24-well micro-titer plates at $18^{\circ} \mathrm{C}$ under a 16:8 h light:dark cycle for $3 \mathrm{wk}$. Copepods were fed 3 times a week with 5 living Artemia $s p$. nauplii. Before exposure to the fish, the numbers of parasites in the body cavity of each copepod was counted under a microscope at $100 \times$ magnification. Copepods infected with 6 live (moving) parasites were selected for fish exposure. 
Infection of sticklebacks. Parental three-spined sticklebacks were caught in the Grosse Plöner See in 2003. For infection experiments, 6 fish families were bred and raised for 7 mo in family groups in $16 \mathrm{l}$ tanks with continuous water supply and aeration at $18^{\circ} \mathrm{C}$ under a 16:8 h light:dark cycle and parasite-free conditions. After initial feeding with live Artemia sp. nauplii, the fish were fed ad libitum 3 times a week with a mixture of frozen chironomid larvae and daphnids. Prior to exposure the fish were marked according to infection dose by clipping 0 to 2 spines (1st dorsal spine $=6$ parasites, 2nd dorsal spine $=12$ parasites, both dorsal spines $=18$ parasites, 1 dorsal and 1 pectoral spine $=24$ parasites, no spine clipped $=$ control fish). Wedekind \& Little (2004) found reduced prevalence of Schistocephalus solidus in stickleback when a spine was clipped $1 \mathrm{wk}$ week post infection, compared to control fish. They concluded that spine-clipping stimulated the immune system of infected fish and increased the clearance of infection. In the present study no significant difference was observed in the hepatosomatic index or G:L ratio between controls and fish that had at least one spine cut (ANOVA: both $\mathrm{p}>0.2$ ), indicating that spine-clipping did not have an effect in the present study. To enhance the consumption of the respective number of copepods, marked fish were starved for $3 \mathrm{~d}$ in individual $1 \mathrm{l}$ aquaria. From each of the 6 fish families we selected randomly 20 individuals, 10 of which we used for Camallanus lacustris exposure and 10 for Anguillicola crassus exposure. Within each family group, 2 fish were offered 1, 2, 3 or 4 copepods (each containing 6 parasite larvae), or 0 copepods for control fish, resulting in 8 exposed and 2 control fish per parasite species and family. These groups of 10 fish were kept in 161 aquaria until dissection.

Dissection of sticklebacks. Of 120 experimental fish, 14 died during the experiment due to technical problems with the water supply of 2 aquaria. A total of 106 fish were available for dissection ( $\mathrm{N}=46$ exposed to Anguillicola crassus, 40 exposed to Camallanus lacustris and 20 controls). For each parasite group and controls from the same aquaria, dissection was performed at $18 \mathrm{wk}$ post exposure on 2 consecutive days. The fish were weighed, measured and dissected, head kidneys were prepared for immunological assays (see next subsection). Livers were removed and weighed to calculate the hepatosomatic index $\left(W_{\text {liver }}: W_{\text {fish }}\right) \times 100$, where $W$ is the wet weight (to the nearest $\mathrm{mg}$ ) of the fish or the liver respectively. The hepatosomatic index is a measure of a fish's metabolic condition including fat reserves and carbohydrates (Wootton 1977, Chellappa et al. 1995). To count $A$. crassus parasites, swim bladders were removed and placed on a glass slide for microscopic examination. To monitor C. lacustris infection, guts were squeezed between 2 glass plates and screened for parasites under a dissection microscope. Individual infection rate was calculated as the number of successfully established parasites relative to the number offered.

Immunological assays. Leukocytes were isolated from the head kidney of dissected sticklebacks ( $\mathrm{N}=$ 106) as described in Kurtz et al. (2004). The number of viable leukocytes (with the exclusion of propidium iodide-positive cells) was enumerated by means of flow cytometry (FACSCalibur, Becton \& Dickinson). Total cell numbers in head kidney leukocyte (HKL) suspensions were determined by the standard cell dilution assay (SCDA, Pechhold et al. 1994) in modified form (Scharsack et al. 2004). Propidium iodide (2 mg $\left.\mathrm{l}^{-1}\right)$ and green fluorescent standard particles $\left(3 \times 10^{4}\right.$, $4 \mu \mathrm{m}$, Polyscience) were added to the suspensions to distinguish standard particles (green fluorescencepositive) from viable HKL (propidium iodide-negative, green fluorescence-negative). Distinct leukocyte subsets were identified according to their characteristic FSC/SSC (forward scatter/side scatter) profiles and analyzed as described in Hammerschmidt \& Kurtz (2005b). The proportions of granulocytes (FSC/ $\mathrm{SSC}^{\text {high}}$ ) and lymphocytes (FSC/SSC ${ }^{\text {low }}$ ) of total viable cells in individual HKL samples were used to calculate G:L ratios.

Respiratory burst activity of the HKL was quantified in a lucigenin-enhanced chemiluminescence assay. The assay was modified after Scott \& Klesius (1981) as described by Kurtz et al. (2004). Cell suspensions (160 $\mu \mathrm{l} \mathrm{well}{ }^{-1}$ with $2 \times 10^{5} \mathrm{HKL}$ ) were added to $20 \mu \mathrm{l}$ lucigenin solution (2.5 $\mathrm{g} \mathrm{l}^{-1} \mathrm{PBS}$ ) well ${ }^{-1}$ in 96-well, flatbottomed micro-titer plates and incubated for $30 \mathrm{~min}$ at $18^{\circ} \mathrm{C}$. Phagocytosis and production of reactive oxygen species was initiated by the addition of $20 \mu \mathrm{l}$ zymosan suspension (7.5 $\mathrm{g} \mathrm{l}^{-1} \mathrm{PBS}$ ). Control cultures received $20 \mu \mathrm{l}$ PBS. Plates were measured for $3 \mathrm{~h}$ at $20^{\circ} \mathrm{C}$ with a micro-titer plate luminometer (Berthold). Luminescence was calculated as relative luminescence units (RLU) for each sample using the WinGlow version 1.25.00003 software.

As a parameter for activation of the adaptive immune system, the relative numbers of proliferating lymphocytes in the $\mathrm{S}$ and $\mathrm{G}_{2-\mathrm{M}}$ phase of the cell cycle were determined by quantification of DNA content. HKL were fixed with ethanol $(100 \mu$ cell suspension, $1.25 \times 10^{6} \mathrm{ml}^{-1}$, in $900 \mu \mathrm{l}$ ice-cold ethanol $98 \%$ ) and stored at $4^{\circ} \mathrm{C}$. Cells were centrifuged $(550 \times g, 10 \mathrm{~min}$, $4^{\circ} \mathrm{C}$ ) and supernatant ethanol removed. Resuspended HKL were incubated with RNAse (500 $\mathrm{mg} \mathrm{l}^{-1} \mathrm{PBS}$ ) for $10 \mathrm{~min}$ at room temperature to remove background labeling of RNA. Propidium iodide (Sigma Aldrich) was added to a final concentration of $7.5 \mathrm{mg} \mathrm{l}^{-1}$ and cells were incubated for $10 \mathrm{~min}$ at room temperature. Individual samples were measured either for $3 \mathrm{~min}$ or 
up to 30000 events with a flow cytometer (Becton Dickinson FACSCalibur). Red fluorescence (propidium iodide) was measured in linear mode. Data were evaluated with the CellQuest Pro 4.02 software. Lymphocytes were identified according to their characteristic FSC/SSC profile. Doublet cells were subtracted from single cells as described by Wersto et al. (2001). Frequencies of lymphocytes in $\mathrm{G}_{0-1}, \mathrm{~S}$ and $\mathrm{G}_{2-\mathrm{M}}$ phases were acquired by DNA content analysis of red fluorescence intensity (propidium iodide labeling) of single cells from the lymphocyte gate.

Statistical analysis. Not only infection rate, but also the number of parasites per fish, was evaluated for each parasite species and infection dose and compared with the immune parameters. For all analyses, residuals were used to eliminate possible effects of fish family and gender. Since the residuals were not normally distributed, we transformed the raw data of infection rate logarithmically, RLU was square-root transformed. For G:L ratio, proliferating lymphocytes $\left(\mathrm{S}+\mathrm{G}_{2-\mathrm{M}}\right.$ lymphocytes) and hepatosomatic index Box-Cox transformation was applied. Full-factorial ANOVA models with parasite species and infection dose as independent variables were calculated. Variables were excluded from the analysis when interactions were not significant. We tested for differences between parasite species and control group as well as for differences between infection doses (control, 6, 12, 18 and 24 parasites) within the 2 parasite species. Where the ANOVA was significant, a post-hoc Tukey-Kramer honestly significant difference (HSD) test was used to detect within-group differences. All tests were performed as 2-tailed tests using JMP version 5.0.1.2 (SAS) with a significance level of $\mathrm{p}<0.05$.

\section{RESULTS}

After 18 wk post exposure, we analyzed 46 (of 48) exposed stickleback Gasterosteus aculeatus in the Anguillicola crassus group, 40 (of 48) G. aculeatus in the Camallanus lacustris group, and 20 control fish. In the A. crassus group, 22 fish were exposed but not infected $(47.8 \%)$, whereas in the C. lacustris group only 8 fish were not infected $(20 \%)$.

Within exposed stickleback groups, exposed but not infected and infected sticklebacks did not show statistically significant differences in the investigated traits (hepatosomatic index, G:L ratio, RLU and $\mathrm{S}+\mathrm{G}_{2-\mathrm{M}}$ lymphocytes) (Student's $t$-test: $N=105$, all $\mathrm{p}=0.216$ ).

Exposure to Anguillicola crassus resulted in a maximum number of 6 parasites fish ${ }^{-1}$, exposure to Camallanus lacustris in a maximum number of 17 parasites per fish ${ }^{-1}$. Over all exposure doses, the total number of C. lacustris per infected stickleback was statistically significantly higher compared to $A$. crassus ( $\chi^{2}$ test: $\left.\chi_{1}^{2}=21.5, \mathrm{p}<0.001\right)$. In the $A$. crassus group the average number (Fig. 1a) of parasites per fish showed no statistically significant difference between infection doses (effect of infection dose: $F_{42,3}=0.7541, \mathrm{p}=$ 0.5262). In C. lacustris-infected stickleback, the number of parasites tended to increase with increasing exposure intensity in the 6,12 and 18 parasite groups, but tended to decrease at the highest dose of 24 parasite larvae (Fig. 1a) (effect of infection dose: $F_{3,36}=$ 2.2096, $\mathrm{p}=0.1038$ ). Infection rates (Fig. 1b) showed statistically significant differences between the 2 parasite species (effect of parasite species: $F_{1,54}=6.5923$, $p=0.0130$ ). Comparison of the least-square means for the C. lacustris group showed that the infection rate tended to be highest for the 12 parasite dose (mean $48.8 \%$ ) and lowest for the 24 parasite dose $(18.7 \%)$ (effect of infection dose: $F_{1,17}=3.7114, \mathrm{p}=0.0709$ ). In the $A$. crassus group no statistically significant difference of infection rate between infection doses was detected (effect of infection dose: $F_{3,42}=1.3313, \mathrm{p}=$ 0.2770).

Immune parameters tested at $18 \mathrm{wk}$ post exposure, did not reveal higher activity of the defense system of infected fish compared to controls (Table 1). Statistically significant differences in the G:L ratio were not detected between Camallanus lacustris and Anguillicola crassus exposure groups nor between either parasite infection and the control group. Within the $C$. lacustris group, exposure to 18 parasites resulted in a

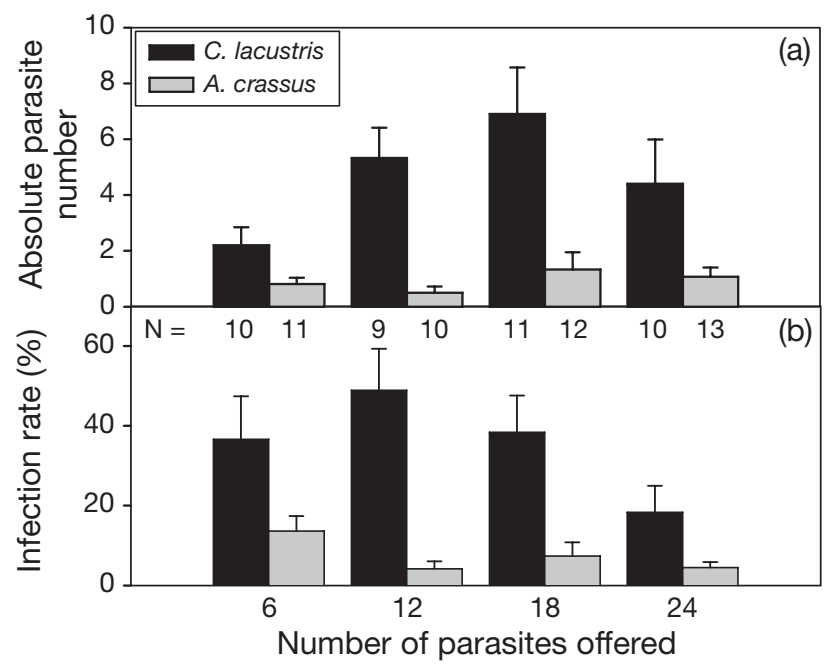

Fig. 1. Gasterosteus aculeatus. Mean (+ SE) (a) absolute number of parasites and (b) infection rate in laboratoryinfected sticklebacks $18 \mathrm{wk}$ post exposure to 4 different doses (i.e. number of parasites offered) of either Camallanus lacustris or Anguillicola crassus. In all infection doses, C. lacustris showed statistically significant higher total numbers of parasites $(p<0.001)$ and infection rates $(p=0.0130)$ than A. crassus 
Table 1. Gasterosteus aculeatus. Mean ( $\pm \mathrm{SE}$ ) granulocyte:lymphocyte (G:L) ratio, respiratory burst reaction from zymosanstimulated cultures (relative luminescence units, $\mathrm{RLU}, \times 10^{5}$ ) and stage $\mathrm{S}+\mathrm{G}_{2-\mathrm{M}}$ lymphocytes (\% of total lymphocytes). Statistically significant p-values (in bold) for the ANOVA models were detected only for G:L ratio in C. lacustris-infected sticklebacks. Superscript ${ }^{a}$ is statistically significantly different from ${ }^{\mathrm{b}}$

\begin{tabular}{|c|c|c|c|c|c|c|c|c|}
\hline \multirow[t]{2}{*}{ Immune trait } & \multicolumn{5}{|c|}{ Exposure intensity (no. parasites) } & & \multirow{2}{*}{$\begin{array}{l}\text { ANOVA } \\
\text { df/error }\end{array}$} & \multirow[b]{2}{*}{$\mathrm{p}$} \\
\hline & 0 & 6 & 12 & 18 & 24 & $F$ & & \\
\hline \multicolumn{9}{|c|}{ Camallanus lacustris } \\
\hline G:L ratio & $0.97 \pm 0.13$ & $0.72^{\mathrm{a}} \pm 0.12$ & $0.62^{\mathrm{a}} \pm 0.06$ & $1.29^{\mathrm{b}} \pm 0.18$ & $0.73 \pm 0.065$ & 4.2629 & $3 / 36$ & 0.0113 \\
\hline RLU & $43.02 \pm 4.68$ & $44.10 \pm 8.15$ & $47.48 \pm 4.87$ & $49.13 \pm 6.55$ & $42.10 \pm 7.68$ & 0.5181 & $3 / 33$ & 0.6728 \\
\hline $\operatorname{Lym} \mathrm{S}+\mathrm{G}_{2-\mathrm{M}}$ & $9.42 \pm 2.73$ & $6.21 \pm 0.89$ & $5.88 \pm 0.48$ & $7.54 \pm 1.25$ & $6.19 \pm 0.88$ & 1.56 & $3 / 22$ & 0.2275 \\
\hline \multicolumn{9}{|c|}{ Anguillicola crassus } \\
\hline G:L ratio & & $0.96 \pm 0.20$ & $0.85 \pm 0.11$ & $0.91 \pm 0.12$ & $0.86 \pm 0.07$ & 0.2232 & $3 / 42$ & 0.8798 \\
\hline RLU & & $47.66 \pm 6.84$ & $45.57 \pm 7.66$ & $34.39 \pm 3.90$ & $43.52 \pm 4.49$ & 1.4683 & $3 / 41$ & 0.2373 \\
\hline $\operatorname{Lym} \mathrm{S}+\mathrm{G}_{2-\mathrm{M}}$ & & $10.63 \pm 2.65$ & $8.21 \pm 2.86$ & $7.06 \pm 0.71$ & $8.69 \pm 1.76$ & 0.3076 & $3 / 26$ & 0.8196 \\
\hline
\end{tabular}

statistically significant higher G:L ratio than exposure to 6 and 12 parasites, but not to non-infected controls (effect of infection dose: $F_{3,36}=4.2629, \mathrm{p}=0.0113$, posthoc test statistically significant) (Table $1, \mathrm{G}$ :L ratio). In the $A$. crassus group, no effect on the G:L ratio of the parasite dose was observed (effect of treatment: $F_{3,42}=$ $0.2232, \mathrm{p}=0.8798$ ). Analysis of total cell counts of HKL did not reveal statistically significant differences between treatment groups (data not shown).

HKL from all fish showed elevated respiratory burst activity in cultures with zymosan (Table 1, RLU) stimulation compared to cultures without zymosan. Cultures without zymosan stimulation did not exceed the detection limit (data not shown). Statistically significant differences in zymosan-induced respiratory burst activity were not detected for the control group and the parasite treatment groups (effect of treatment: $F_{3,74}=$ 0.5291, p = 0.6636). Also, no effect was found between the different infection doses (Anguillicola crassus: $F_{3,41}=1.4683, \mathrm{p}=0.2373$, Camallanus lacustris: $F_{3,33}=$ $0.5181, \mathrm{p}=0.6728)$. Proliferation of HKL (\% $\mathrm{S}+\mathrm{G}_{2-\mathrm{M}}$ lymphocytes) showed differences between stickleback exposed to C. lacustris and A. crassus as a trend (effect of parasite: $F_{1,54}=3.4351, \mathrm{p}=0.0693$ ) but did not show statistically significant differences between treatment doses (Table 1).

As a measure of energy stored by the fish we determined their hepatosomatic index. There was no statistically significant difference in hepatosomatic index between the control and the Anguillicola crassus and Camallanus lacustris groups (effect of treatment: $F_{2,102}$ $=0.5573, p=0.5745$ ) (Fig. 2). Exposure to different parasite doses had no statistically significant effect on the hepatosomatic index of the fish independent of parasite species (Fig. 2, effect of treatment: $F_{4,100}=1.3657$, $\mathrm{p}=0.2513$ ). However, although not statistically significant in the ANOVA model, fish with the highest parasite load in the group of C. lacustris (18 parasites

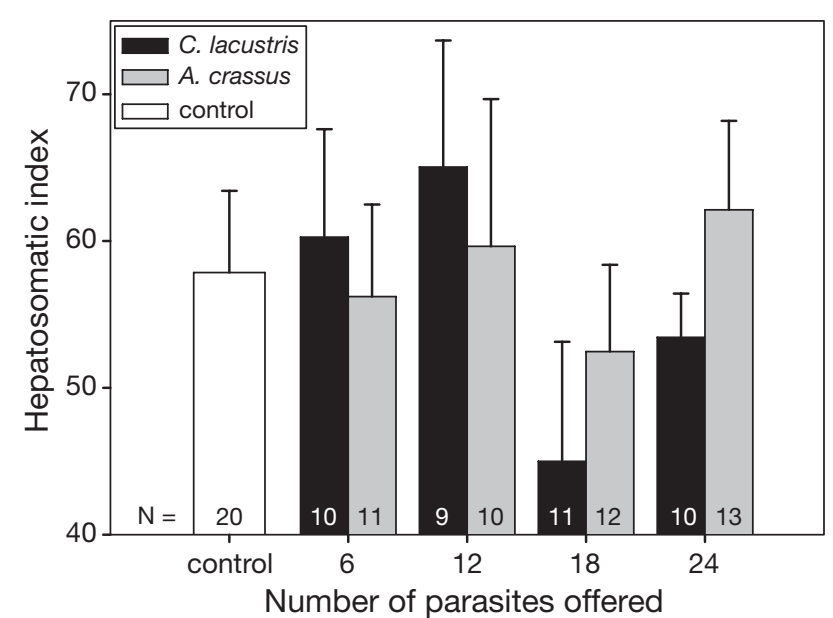

Fig. 2. Gasterosteus aculeatus. Mean (+SE) fish condition calculated by hepatosomatic index for fish exposed to 4 different doses (i.e. number of parasites offered) of either Camallanus lacustris or Anguillicola crassus and for nonexposed control group

offered, infested mean: $7 \pm 1.66)$ tended to have a lower hepatosomatic index than fish in the group exposed to 12 parasites (infested mean: $5.3 \pm 1.08$, post hoc $t$-test: $\mathrm{p}=0.055$ ) (Fig. 2).

\section{DISCUSSION}

Camallanus lacustris has long been established in fish populations in Europe, whereas Anguillicola crassus was introduced in the 1980s (Neumann 1985, Kirk 2003). Since then, A. crassus has spread all over Europe and is a serious threat for the European eel Anguilla anguilla as definitive host (Kirk 2003). Both parasite species can be transmitted by paratenic host fish, but little is known about infection dynamics in these hosts. The present study investigated infection of 
a paratenic host, the three-spined stickleback Gasterosteus aculeatus with C. lacustris and A. crassus. The laboratory infection levels described here were in the range observed in wild stickleback populations for A. crassus (Haenen \& van Banning 1990, Thomas \& Ollevier 1992) and C. lacustris (Kalbe et al. 2002). In our experiment, exposure to equal doses of the 2 parasites resulted in statistically significantly higher numbers of $C$. lacustris than A. crassus. Thus, higher numbers of $C$. lacustris than $A$. crassus observed in wild-caught stickleback (Kalbe et al. 2002) are probably not caused by differences in exposure. In C. lacustris-infected stickleback, infection rate and total number of parasites tended to show dose-dependent maxima after exposure to 12 and 18 parasites respectively. Although this trend was not statistically significant, it does indicate an optimum infection dose for $C$. lacustris. In the $A$. crassus group, infection rate was low and dose effects were not detectable.

Knopf \& Mahnke (2004) investigated the infection success of Anguillicola crassus in its natural definitive host, the Japanese eel Anguilla japonica and the recently affected European eel A. anguilla. Knopf \& Mahnke (2004) found that the new host, the European eel was more susceptible to A. crassus infection than the Japanese eel; i.e. the parasite was more successful in a new host. In our experiments, the parasite was more successful in the established host-parasite system, (Camallanus lacustris-Gasterosteus aculeatus) than in the new host-parasite system (A. crassus-G. aculeatus).

Although changes in the G:L ratio in Camallanus lacustris-infected fish indicate activation of the immune system, no statistically significant differences in hepatosomatic index due to exposure or infection were observed. We expected a decrease in the condition of the sticklebacks since immunity is supposed to be costly (Moret \& Schmidt-Hempel 2000). Wegner et al. (2003) found a condition decrease in highly parasitized sticklebacks after laboratory infection. However, in our experiment, the impact of infection might have been too low to have had a detectable effect on the hepatosomatic index. Furthermore fish reared under favorable laboratory conditions (e.g. with ad libitum feeding) may be able to compensate the impact of infection on their body condition (Candolin \& Voigt 2001).

The extent to which the immune response of the stickleback influenced infection success in our study remains unclear. For Anguillicola crassus, the less successful parasite, obvious activity of the defense system was not detected, but the sampling time-point (18 wk post exposure) was probably too late to reveal acute immune responses. In Camallanus lacustris-infected sticklebacks, an elevated G:L ratio was observed in the group exposed to 18 parasites (with the highest para- site load), while G:L ratios were lower in the groups exposed to 6 and 12 C. lacustris. There were no statistically significant differences between the G:L ratios of non-infected controls and C. lacustris groups exposed to 6 and 12 (low G:L ratios) and 18 (high G:L ratios) parasites. Therefore, it is not possible to say whether statistically significant differences between the exposure groups were due to a decrease in the G:L ratios of groups exposed to 6 and 12 parasites or to an increase in the G:L ratio in the group exposed to 18 parasites. Fluctuating recruitment of granulocytes from the head kidney due to the parasite load could explain the high G:L ratios at the exposure dose of 18 parasites and the low values at doses of 6 and 12 parasites. Dose effects on the G:L ratio were not influenced by fluctuations in total numbers of HKL, as total cell counts did not reveal statistically significant differences between treatment groups. Neither parasite had statistically significant effects on respiratory burst activity or lymphocyte proliferation of HKL. Analysis of immune parameters at earlier time-points during both infections will be necessary to reveal the underlying mechanisms and kinetics.

In summary, the neozoic Anguillicola crassus was less successful at infecting its paratenic host, the threespined stickleback, than the long-established Camallanus lacustris. For C. lacustris, however, the high infection rate and the potential dose response observed in our experiments suggest a high degree of adaptation to the stickleback as paratenic host.

Acknowledgements. We are grateful to W. Derner, R. Leipnitz, L. Janke, G. Augustin and M. Wulf for technical assistance during the experiments and to F. Kirfel and J. Schütt from the Fischerei Reese for providing the perch. Thanks to all of the people in our department for fruitful discussion; I. Jäger, K. Hammerschmidt, S. Yeates and M. Milinski gave helpful comments on the manuscript. Thanks to the anonymous reviewers, whose critical comments were extensively used to improve the manuscript.

\section{LITERATURE CITED}

Birkhead TR (1998) Sperm competition in birds. Rev Reprod 3:123-129

Buchmann K, Sigh J, Nielsen CV, Dalgaard M (2001) Host responses against the fish parasitizing ciliate Ichthyophthirius multifiliis. Vet Parasitol 100:105-116

Candolin U, Voigt HR (2001) No effect of a parasite on reproduction in stickleback males: a laboratory artefact? Parasitology 122:457-464

Chellappa S, Huntingford FA, Strang RHC, Thomson RY (1995) Condition factor and hepatosomatic index as estimates of energy status in male three-spined stickleback. J Fish Biol 47:775-787

Haenen OLM, van Banning P (1990) Detection of larvae of Anguillicola crassus (an eel swim bladder nematode) in freshwater fish species. Aquaculture 87:103-109 
Hamers R, Goerlich R (1996) Flow cytometric DNA analysis of the haematopoietic tissue of carp Cyprinus carpio during experimental infection with the haemoflagellate Trypanoplasma borreli. Dis Aquat Org 24:119-134

Hammerschmidt K, Kurtz J (2005a) Surface carbohydrate composition of a tapeworm in its consecutive intermediate hosts: individual variation and fitness consequences. Int $\mathrm{J}$ Parasitol 35:1499-1507

Hammerschmidt K, Kurtz J (2005b) Evolutionary implications of the adaptation to different immune systems in a parasite with a complex life cycle. Proc R Soc Lond B 272: 2511-2518

Hoole D, Lewis JW, Schuwerack PMM, Chakravarthy C, Shrive AK, Greenhough TJ, Cartwright JR (2003) Inflammatory interactions in fish exposed to pollutants and parasites: a role for apoptosis and $\mathrm{C}$ reactive protein. Parasitology 126:71-85

Jones SRM (2001) The occurrence and mechanisms of innate immunity against parasites in fish. Dev Comp Immunol 25: 841-852

Kalbe M, Wegner KM, Reusch TBH (2002) Dispersion patterns of parasites in 0+ year three-spined sticklebacks: a cross population comparison. J Fish Biol 60:1529-1542

Kirk RS (2003) The impact of Anguillicola crassus on European eels. Fish Manag 10:385-94

Knopf K, Mahnke M (2004) Differences in susceptibility of the European eel (Anguilla anguilla) and the Japanese eel (Anguilla japonica) to the swim-bladder nematode Anguillicola crassus. Parasitology 129:491-496

Knopf K, Naser K, van der Heijden MHT, Taraschewski H (2000) Humoral immune response of European eel Anguilla anguilla experimentally infected with Anguillicola crassus. Dis Aquat Org 42:61-69

Kurtz J (2004) Memory in the innate and adaptive immune systems. Microbes Infect 6:1410-1417

Kurtz J, Kalbe M, Aeschlimann PB, Haberli MA, Wegner KM, Reusch TBH, Milinski M (2004) Major histocompatibility complex diversity influences parasite resistance and innate immunity in sticklebacks. Proc R Soc Lond B 271: 197-204

Lodes MJ, Yoshino TP (1985) Population dynamics and histopathology of Spinitectus carolini and Camallanus oxycephalus in striped bass of Lake Texoma. Trans Am Microsc Soc 104:110

Meguid MA, Eure HE (1996) Pathobiology associated with the spiruroid nematodes Camallanus oxycephalus and Spinitectus carolini in the intestine of green sunfish, Lepomis cyanellus. J Parasitol 82:118-123

Molnar K, Szakolczai J, Vetesi F (1995) Histological changes in the swim bladder wall of eels due to abnormal location of adults and 2nd stage larvae of Anguillicola crassus. Acta Vet Hung 43:125-137

Moravec F (1969a) On the problem of host specificity, reservoir parasitism and secondary invasions of Camallanus lacustris (Zoega, 1776) (Nematoda: Camallanidae). Helminthologia 10:1-4

Moravec F (1969b) Observations on the development of Camallanus lacustris (Zoega, 1776) (Nematoda: Camallanidae). Vestn Cesk Spol Zool 33:15-33

Moravec F (1994) Parasitic nematodes of freshwater fishes of Europe. Kluwer Academic Publishers, Dordrecht

Moret Y, Schmidt-Hempel P (2000) Survival for immunity: the price of immune system activation for bumblebee workers. Science 290:1166-1168

Mulcahy G, O'Neill S, Fanning J, McCarthy E, Sekiya M (2005) Tissue migration by parasitic helminths - an immunoevasive strategy? Trends Parasitol 21:273-277
Neumann W (1985) Schwimmblaseparasit Anguillicola bei Aalen. Fisch Teichwirt 11:322

Nie P, Hoole D (2000) Effects of Bothriocephalus acheilognathi on the polarization response of pronephric leucocytes of carp, Cyprinus carpio. J Helminthol 74:253-257

Nie P, Hoole D, Arme C (1996) Proliferation of pronephric lymphocytes of carp, Cyprinus carpio induced by extracts of Bothriocephalus acheilognathi. J Helminthol 70: 127-131

Pechhold K, Pohl T, Kabelitz D (1994) Rapid quantification of lymphocyte subsets in heterogeneous cell populations by flow-cytometry. Cytometry 16:152-159

Reite OB, Evensen O (2006) Inflammatory cells of teleostean fish: a review focusing on mast cells/eosinophilic granule cells and rodlet cells. Fish Shellfish Immunol 20: 192-208

Rijkers GT, Frederix-Wolters EM, van Muiswinkel WB (1980) The immune system of cyprinid fish. Kinetics and temperature dependence of antibody-producing cells in carp (Cyprinus carpio). Immunology 41:91-97

Roberts ML, Lewis JW, Wiegertjes GF, Hoole D (2005) Interaction between the blood fluke, Sanguinicola inermis and humoral components of the immune response of carp, Cyprinus carpio. Parasitology 131:261-271

Rolbiecki L (2004) Larvae of Anguillicola crassus (Nematoda, Dracunculoidea) in stickleback (Gasterosteus aculeatus) and smelt (Osmerus eperlanus) from the Gulf of Gdansk and the Vistula Lagoon. Zool Pol 49:29-35

Scharsack JP, Steinhagen D, Korting W, Leibold W, Schuberth HJ (2000) Flow cytometric analysis of proliferative responses of carp Cyprinus carpio peripheral blood leukocytes to mitogens and to the hemoflagellate Trypanoplasma borreli. Dis Aquat Org 41:203-210

Scharsack JP, Kalbe M, Derner R, Kurtz J, Milinski M (2004) Modulation of granulocyte responses in three-spined sticklebacks Gasterosteus aculeatus infected with the tapeworm Schistocephalus solidus. Dis Aquat Org 59: $141-150$

Scott AL, Klesius PH (1981) Chemiluminescence: a novel analysis of phagocytosis in fish. Dev Biol Stand 49: $243-254$

Stumpp M (1975) Investigations on morphology and biology of Camallanus cotti (Fujita, 1927). Parasitol Res 46: $277-290$

Szekely C (1996) Experimental studies on the infectivity of Anguillicola crassus third-stage larvae (Nematoda) from paratenic hosts. Folia Parasitol (Ceske Budejovice) 43: 305-311

Taraschewski H, Renner C, Mehlhorn H (1988) Treatment of fish parasites. 3. Effects of levamisole $\mathrm{HCl}$, metrifonate, fenbendazole, mebendazole, and ivermectin on Anguillicola crassus (nematodes) pathogenic in the air bladder of eels. Parasitol Res 74:281-289

Thomas K, Ollevier F (1992) Paratenic hosts of the swim bladder nematode Anguillicola crassus. Dis Aquat Org 13: $165-174$

Tully O, Nolan DT (2002) A review of the population biology and host-parasite interactions of the sea louse Lepeophtheirus salmonis (Copepoda: Caligidae). Parasitology 124: 165-182

Wedekind C, Little TJ (2004) The clearance of hidden cestode infection triggered by an independent activation of host defense in a teleost fish. J Parasitol 90:1329-1331

Wegner KM, Kalbe M, Kurtz J, Reusch TBH, Milinski M (2003) Parasite selection for immunogenetic optimality. Science 301:1343

Wersto RP, Chrest FJ, Leary JF, Morris C, Stetler-Stevenson 
M, Gabrielson E (2001) Doublet discrimination in DNA cell-cycle analysis. Cytometry 46:296-306

Whyte SK, Chappell LH, Secombes CJ (1989) Cytotoxic reactions of rainbow trout, Salmo gairdneri Richardson, macrophages for larvae of the eye fluke Diplostomum pseudospathacum (Digenea). J Fish Biol 35:333-345

Wiegertjes GF, Forlenza M, Joerink M, Scharsack JP (2005) Parasite infections revisited. Dev Comp Immunol 29:749-758

Editorial responsibility: David Marcogliese, Montréal, Quebec, Canada
Wootton RJ (1977) Effect of food limitation during the breeding season on the size, body components and egg production of female sticklebacks (Gasterosteus aculeatus). J Anim Ecol 46:823-834

Würtz J, Taraschewski H (2000) Histopathological changes in the swim bladder wall of the European eel Anguilla anguilla due to infections with Anguillicola crassus. Dis Aquat Org 39:121-134

Submitted: May 8, 2006; Accepted: November 15, 2006 Proofs received from author(s): February 9, 2007 